\title{
Effect of Heat Moisture Treatment Conditions on Swelling Power and Water Soluble Index of Different Cultivars of Sweet Potato (Ipomea batatas (L). Lam) Starch
}

\author{
Suraji Senanayake, ${ }^{1}$ Anil Gunaratne, ${ }^{2}$ KKDS Ranaweera, ${ }^{1}$ and Arthur Bamunuarachchi ${ }^{3}$ \\ ${ }^{1}$ Department of Food Science \& Technology, University of Sri Jayewardenepura, Sri Lanka \\ ${ }^{2}$ Faculty of Agricultural Sciences, Sabaragamuwa University of Sri Lanka, Belihuloya, Sri Lanka \\ 3 “ON-SITE” Consultancy, Training \& Trade Systems, 128/22, Poorwarama Road, Kirulapone, 5 Colombo, Sri Lanka
}

Correspondence should be addressed to Suraji Senanayake; surajisena@gmail.com

Received 6 May 2013; Accepted 11 July 2013

Academic Editors: J. B. Alvarez and C. Ramsey

Copyright (C) 2013 Suraji Senanayake et al. This is an open access article distributed under the Creative Commons Attribution License, which permits unrestricted use, distribution, and reproduction in any medium, provided the original work is properly cited.

\begin{abstract}
A study was done to analyse the change in swelling power (SP) and the water soluble index (WSI) of native starches obtained from five different cultivars of sweet potatoes (swp 1 (Wariyapola red), swp 3 (Wariyapola white), swp 4 (Pallepola variety), swp 5 (Malaysian variety), and swp 7 (CARI 273)) commonly consumed in Sri Lanka. Extracted starch from fresh roots, two to three days after harvesting has been modified using 20\%, 25\%, and $30 \%$ moisture levels and heated at $85^{\circ} \mathrm{C}$ and $120^{\circ} \mathrm{C}$ for 6 hours and determined the SP and WSI. Results were subjected to general linear model, and analysis of variance (ANOVA) was carried out by using MINITAB version 14 . Overall results showed a significantly high level $(P<0.05)$ of SP and WSI in all the cultivars of moisture-temperature treated starches than their native starch. Correlation analysis showed an effect on SP with the variation in the cultivar, temperature, and moisture; temperature combination and moisture alone had no significant effect. Significantly high levels of swelling power $(P>0.05)$ were observed in $20 \%-85^{\circ} \mathrm{C}$, and $30 \%-120^{\circ} \mathrm{C}$ and the highest amount of swelling in the modified starch than its native form was observed in swp 7 cultivar. Results revealed a nonlinear relationship in the WSI with the cultivar type, moisture level, and the lower moisture-temperature combinations but higher temperature-moisture combinations had a significant effect. SP and WSI had a slight positive linear relationship according to analysis. Based on the results, a significantly high level of swelling and water solubility of native starches of different cultivars of sweet potatoes can be achieved by changing the moisture content to $30 \%$ and heating at $120^{\circ} \mathrm{C}$ for 6 hours.
\end{abstract}

\section{Introduction}

For a wide range of starch applications, native starches cannot be used due to inability to bring out the desired properties. Native starches can be modified to obtain the desired qualities by starch modification methods. Chemical modification of starch molecules is commonly used in achieving the desired properties. Also by using specific moisture and temperature conditions, some physicochemical properties of starch can be altered. There are more trends in the world for physical modification of starch which is used in food industrial applications as there is an increasing difficulty in obtaining regulatory approval of the new chemical reagents and higher levels of treatment as described by BeMiller [1]. Since most physical modifications involve only water and heat, these hydrothermal treatments are considered to be natural and safe materials by Jacobs and Delcour [2].

Two basic types of heat-moisture treatments are commonly employed in modifying the physicochemical properties of starch [3]. This involves the storage of starch at specific levels of moisture and heat for a specific period of time without causing a significant level of starch gelatinization. Treatment of starch with excess moisture is referred to as "annealing" [4-6], and the term "heat-moisture treatment" (HMT) is used when restricted levels of moisture are applied in the literature $[7,8]$. These two types of physical modifications occur at temperatures above the glass transition temperatures of the relevant starch and often below the gelatinization 
temperatures which depend on the specific moisture contents used for the treatment. Heat-moisture treatment effect on changing the functional properties of wheat, maize, potato, barley, cassava, yam, and legume starches were reported by many researchers [8-11]. It was observed that the HMT has increased the gelatinization temperature, enzymatic susceptibility, solubility, swelling volume, and changes in the X-ray diffraction patterns. The changes in these parameters vary depending on the source of the starch and the HMT conditions.

Temperature and moisture conditions are often selected without considering the exact gelatinization temperature of the starch at that particular moisture level, and the observed results on HMT may have been affected by the partial gelatinization of starch [12]. Not much work was done or reported on the effects of HMT at different combinations of temperature-moisture levels and treatment times on the properties of sweet potato starch. This study was done to observe the effect of different heat-moisture conditions on the swelling power and the water soluble index of five different cultivars of sweet potato (Ipomea batatas (L). Lam) starch.

\section{Materials and Methods}

Matured tubers of sweet potatoes, namely, swp 1 (Wariyapola red), swp 5 (Malaysian variety), swp 7 (CARI 273), swp 3 (Wariyapola white), and swp 4 (Pallepola variety) were collected from different areas in Dambulla, Gokarella, and Horana regions, Sri Lanka. Random samples selected from market areas have been identified at the Horticultural Crop Research and Development Institute, Gannoruwa, Kandy, Sri Lanka. Starch samples were prepared two to three days after harvesting.

2.1. Starch Extraction. Starch separation was carried out according to the method described by Takeda et al. [13] with slight modifications. Fresh tubers were washed, peeled, diced, and dipped in ice water containing $100 \mathrm{ppm}$ sodium metabisulphite to minimize browning. Diced sample was wet milled at low speed in a laboratory scale blender with $1: 2 \mathrm{w} / \mathrm{v}$ of tap water for 2 minutes and filtered through a gauze cloth. Residue was repeatedly wet milled and filtered for thrice, and suspension was kept overnight for settling of starch. The supernatant was decanted, and the settled residue was further purified with repeated suspension in tap water $(1: 2 \mathrm{v} / \mathrm{v})$ followed by the settling for 3 hours. The purified starch was dried at $35^{\circ} \mathrm{C}$, sifted through $300 \mu \mathrm{m}$ sieve, sealed, and packed for analysis.

2.2. Heat-Moisture Treatment (HMT). Starch samples (20 g) were adjusted to $20 \%, 25 \%$, and $30 \%$ moisture levels and placed in tubes with a sealing cap and equilibrated at room temperature for 12 hours. Samples were heated at $85^{\circ} \mathrm{C}$ and $120^{\circ} \mathrm{C}$ for 6 hours. Occasional shaking was done to samples within the treatment period for homogeneous distribution of moisture. After treatment, the samples were cooled to room temperature and dried at $40^{\circ} \mathrm{C}$ to a uniform moisture level of $10 \%$ and equilibrated at room temperature for 2 days.
2.3. Swelling Power (SP) and Water Soluble Index (WSI). Swelling power (SP) of the native and the HMT treated starch was determined according to the method of Gunaratne et al. [14]. Starch $(100 \mathrm{mg}, \mathrm{db})$ was weighed directly into a screwcap test tube, and $10 \mathrm{~mL}$ distilled water was added. The capped tubes were placed on a vortex mixer for 10 seconds and incubated at $85^{\circ} \mathrm{C}$ water bath for 30 minutes with frequent mixing. The tubes were cooled to room temperature in an iced water bath and centrifuged at $2000 \times \mathrm{g}$ for 30 minutes; the supernatant was removed, and the remaining sediment in the tube was weighed $\left(W_{s}\right)$. The supernatant was dried to constant weight $\left(W_{1}\right)$ in a drying oven at $100^{\circ} \mathrm{C}$. The water swelling power was calculated as follows:

$$
\mathrm{SP}=\frac{W_{s}}{[0.1 \times(100 \%-\mathrm{WSI})]}(\mathrm{g} / \mathrm{g}),
$$

where WSI $=W_{1} / 0.1 \times 100 \%$.

2.4. Statistical Analysis. Results were subjected to general linear model, and analysis of variance (ANOVA) and correlation analysis for this study were carried out by using MINITAB version 14 .

\section{Results and Discussion}

Results showed a significantly high level $(P<0.05)$ of swelling power and water soluble index in all the cultivars of HMT starch than their native starch (Tables 1 and 2). Also the results indicated a significant effect of cultivar, temperature, and moisture-temperature combination on the variation of SP in HMT starch and also showed no effect from the used moisture contents $(P<0.05)$. Correlation analysis showed a significant level of influence on SP by the moisture-temperature combination (Figure 1).

Lowest level of SP was found in the native starch of Swp 7 and comparatively high level of increase in SP was observed after the heat-moisture treatment, than the other cultivars. High level of swelling in all the cultivars of HMT starch than the native starch may be due to the amylose which complex with lipids in starch granules that are in helical form may change its physical form due to HMT and becomes more amorphous so that it can readily combine with moisture and increase swelling. But in most recent studies by researchers [8, 15] revealed a decrease in swelling with varying levels of HMT.

There is no significant difference $(P>0.05)$ in SP in the moisture-temperature combinations, $20 \%, 85^{\circ} \mathrm{C}, 20 \%-85^{\circ} \mathrm{C}$, $20 \%-120^{\circ} \mathrm{C}$, and $25 \%-120^{\circ} \mathrm{C}$. Combinations of $25 \%-85^{\circ} \mathrm{C}$, and $30 \%-85^{\circ} \mathrm{C}$-had the lowest SP at the level $P>0.05$, and significantly highest level of SP was observed in the 30\%$120^{\circ} \mathrm{C}$-combination. From the total correlation analysis of moisture-temperature combination, significantly high levels of SP $(P>0.05)$ were observed in $20 \%-85^{\circ} \mathrm{C}$, and $30 \%-$ $120^{\circ} \mathrm{C}$. Therefore, $20 \%-85^{\circ} \mathrm{C}$ - can be used economically in increasing the swelling power of native starch.

Correlation analysis revealed there is no significant effect $(P<0.05)$ on WSI from the cultivar type, moisture level, and the moisture-temperature combination (Figure 2) but temperature affects the WSI significantly. Therefore, all moisture levels with $120^{\circ} \mathrm{C}$ temperature showed higher WSI than 
TABLE 1: Changes in swelling power (g/g) of different sweet potato starches after $6 \mathrm{hr}$ HMT.

\begin{tabular}{|c|c|c|c|c|c|c|}
\hline \multicolumn{2}{|c|}{ Native starch } & $\begin{array}{c}\text { Swp 1 } \\
7.9 \pm 0.1^{\mathrm{e}}\end{array}$ & $\begin{array}{c}\text { Swp 3 } \\
8.7 \pm 0.2^{\mathrm{d}}\end{array}$ & $\begin{array}{c}\text { Swp } 4 \\
8.7 \pm 0.1^{\mathrm{d}}\end{array}$ & $\begin{array}{c}\text { Swp } 5 \\
8.0 \pm 0.1^{\mathrm{e}} \\
\end{array}$ & $\begin{array}{c}\text { Swp } 7 \\
5.8 \pm 0.1^{\mathrm{d}}\end{array}$ \\
\hline Temperature & Moisture & & & & & \\
\hline \multirow{3}{*}{$85^{\circ} \mathrm{C}$} & $20 \%$ & $11.5 \pm 1.2^{\mathrm{d}}$ & $12.0 \pm 0.9^{\mathrm{a}}$ & $12.5 \pm 0.8^{\mathrm{a}}$ & $12.1 \pm 0.2^{c}$ & $8.5 \pm 0.7^{\mathrm{c}}$ \\
\hline & $25 \%$ & $12.9 \pm 0.5^{\mathrm{d}}$ & $10.5 \pm 0.5^{\mathrm{b}, \mathrm{c}}$ & $11.4 \pm 0.2^{\mathrm{b}}$ & $11.0 \pm 0.6^{\mathrm{c}}$ & $5.8 \pm 0.3^{\mathrm{d}}$ \\
\hline & $30 \%$ & $13.9 \pm 0.2^{\mathrm{a}, \mathrm{c}}$ & $10.1 \pm 0.3^{b}$ & $10.3 \pm 0.4^{c}$ & $9.7 \pm 0.7^{\mathrm{d}}$ & $5.4 \pm 0.2^{\mathrm{d}}$ \\
\hline \multirow{3}{*}{$120^{\circ} \mathrm{C}$} & $20 \%$ & $15.4 \pm 0.3^{\mathrm{a}}$ & $10.5 \pm 0.3^{b}$ & $12.6 \pm 0.2^{\mathrm{a}}$ & $11.8 \pm 0.1^{c}$ & $10.0 \pm 0.2^{\mathrm{b}}$ \\
\hline & $25 \%$ & $15.7 \pm 0.2^{\mathrm{a}, \mathrm{b}}$ & $11.6 \pm 0.1^{\mathrm{a}, \mathrm{b}}$ & $11.7 \pm 0.2^{\mathrm{a}, \mathrm{b}}$ & $13.1 \pm 0.1^{\mathrm{b}}$ & $10.3 \pm 0.1^{\mathrm{b}}$ \\
\hline & $30 \%$ & $14.3 \pm 0.2^{\mathrm{a}, \mathrm{b}, \mathrm{c}}$ & $10.1 \pm 0.1^{\mathrm{b}, \mathrm{c}}$ & $12.8 \pm 0.1^{\mathrm{a}}$ & $15.1 \pm 0.1^{\mathrm{a}}$ & $12.1 \pm 0.1^{\mathrm{a}}$ \\
\hline
\end{tabular}

Values represented by different superscripts in each column are different at $P>0.05$ level.

TABLE 2: Variation of water soluble index (\%) in different sweet potato starches after $6 \mathrm{hr}$ HMT.

\begin{tabular}{|c|c|c|c|c|c|c|}
\hline \multirow{2}{*}{\multicolumn{2}{|c|}{ Native starch }} & Swp 1 & Swp 3 & Swp 4 & Swp 5 & Swp 7 \\
\hline & & $1.6 \pm 0.1^{\mathrm{d}}$ & $1.8 \pm 0.1^{\mathrm{f}}$ & $1.3 \pm 0.1^{\mathrm{e}}$ & $2.1 \pm 0.1^{\mathrm{e}}$ & $0.5 \pm 0.1^{\mathrm{d}}$ \\
\hline \multirow[t]{2}{*}{ Temperature } & Moisture & & & & & \\
\hline & $20 \%$ & $3.9 \pm 0.2^{c}$ & $3.2 \pm 0.3^{\mathrm{e}}$ & $4.2 \pm 0.3^{\mathrm{d}}$ & $4.1 \pm 0.3^{\mathrm{d}}$ & $2.8 \pm 0.3^{\mathrm{c}}$ \\
\hline \multirow[t]{3}{*}{$85^{\circ} \mathrm{C}$} & $25 \%$ & $3.3 \pm 0.4^{c}$ & $4.1 \pm 0.4^{\mathrm{d}}$ & $5.0 \pm 0.1^{\mathrm{b}, \mathrm{c}}$ & $2.3 \pm 0.6^{\mathrm{e}}$ & $3.5 \pm 0.5^{\mathrm{c}}$ \\
\hline & $30 \%$ & $8.6 \pm 0.6^{\mathrm{a}, \mathrm{b}}$ & $5.6 \pm 0.2^{c}$ & $6.1 \pm 0.3^{f}$ & $4.1 \pm 0.3^{\mathrm{d}}$ & $2.4 \pm 0.2^{\mathrm{c}}$ \\
\hline & $20 \%$ & $9.2 \pm 0.2^{\mathrm{a}}$ & $8.5 \pm 0.5^{b}$ & $4.7 \pm 0.2^{c}$ & $6.6 \pm 0.2^{c}$ & $7.8 \pm 0.1^{\mathrm{b}}$ \\
\hline \multirow[t]{2}{*}{$120^{\circ} \mathrm{C}$} & $25 \%$ & $9.0 \pm 0.2^{\mathrm{a}}$ & $9.6 \pm 0.1^{\mathrm{a}}$ & $5.5 \pm 0.2^{\mathrm{b}}$ & $11.5 \pm 0.3^{\mathrm{a}}$ & $8.2 \pm 0.1^{\mathrm{b}}$ \\
\hline & $30 \%$ & $8.1 \pm 0.1^{b}$ & $8.5 \pm 0.1^{\mathrm{b}}$ & $7.7 \pm 0.2^{\mathrm{a}}$ & $9.1 \pm 0.2^{\mathrm{b}}$ & $13.5 \pm 0.3^{\mathrm{a}}$ \\
\hline
\end{tabular}

Values represented by different superscripts in each column are different at $P>0.05$ level.

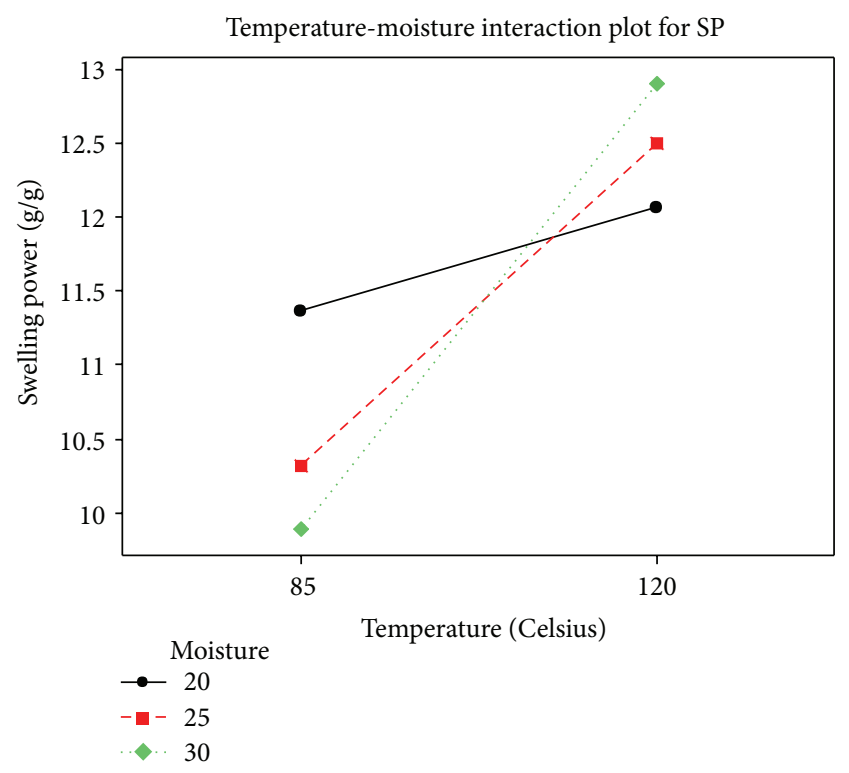

FIGURE 1: Temperature-moisture combined effect on swelling power (SP) of different starches.

the combinations at $85^{\circ} \mathrm{C}$. From all the combinations $30 \%$ moisture and $120^{\circ} \mathrm{C}$ had the highest level of WSI (Table 2).

Previous studies indicate different trends of change in solubility or WSI in various starches due to $\operatorname{HMT}[8,15]$. This may be also due to the fact that physical change in starch granules due to heat-moisture treatment. Our results indicate that the higher temperature used for HMT had more

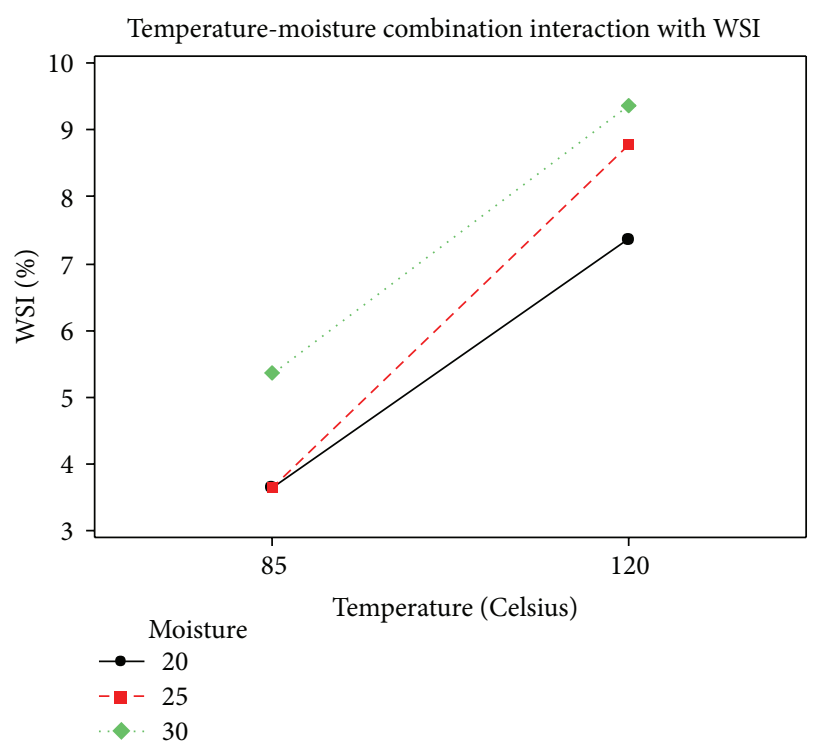

FIGURE 2: Temperature-moisture combined effect on WSI of different starches.

WSI than the lower temperature used. Higher solubility of starch may be due to the degradation of starch at higher temperatures. When considering the relationship between SP and WSI, there is a slight positive linear correlation (Pearson correlation coefficient 0.489 ). Analysis also indicated that there is no significant effect $(P<0.05)$ on the SP and WSI relationship from the cultivar type and moisture but slight effect from the temperature. 
Overall results for HMT of native starch for $6 \mathrm{hrs}$ have shown increased levels of SP and WSI than the native starch, and it is recommended to carry out the observations for different time periods with more variations in moisturetemperature combinations to get a more conclusive idea in this area.

\section{Conclusion}

The application of HMT on native starch showed increased levels of swelling and solubility thus obtained higher values for SP and WSI than their native counterparts. Results indicated a significant level of effect from moisture-temperature combination on SP and increase in WSI due to high level of temperature. Overall results showed the highest level of SP and WSI in moisture-temperature combination of 30\%$120^{\circ} \mathrm{C}$, and swp 7 cultivar had the highest level of increase in SP and WSI than its native form compare to other cultivars.

\section{References}

[1] J. N. BeMiller, "Starch modification: challenges and prospects," Starch, vol. 49, no. 4, pp. 127-131, 1997.

[2] H. Jacobs and J. A. Delcour, "Hydrothermal modification of granular starch, with retention of the granular structure: a review," Journal of Agricultural and Food Chemistry, vol. 46, no. 8, 1998.

[3] R. Stute, "Hydrothermal modification of starches: the difference between annealing and heat-moisture treatment," Starch, vol. 44, no. 6, pp. 205-214, 1992.

[4] H. Jacobs, R. C. Earlingen, S. Clauwaert, and J. A. Delcour, "Influence of annealing on the pasting properties of starches from varying botanical sources," Cereal Chemistry, vol. 72, pp. 480-4487, 1995.

[5] C. A. Knutson, "Annealing of maize starches at elevated temperatures," Cereal Chemistry, vol. 67, pp. 376-384, 1990.

[6] I. Larsson and A. C. Eliasson, "Annealing of starch at intermediate water content," Starch, vol. 43, no. 6, pp. 227-2231, 1991.

[7] L. S. Collado and H. Corke, "Heat-moisture treatment effects on sweet potato," Food Chemistry, vol. 65, no. 3, pp. 339-346, 1999.

[8] R. Hoover, T. Vasanthan, N. J. Senanayake, and A. M. Martin, "The effects of defatting and heat-moisture treatment on the retrogradation of starch gels from wheat, oat, potato, and lentil," Carbohydrate Research, vol. 261, no. 1, pp. 13-24, 1994.

[9] T. E. Abraham, "Stabilization of paste viscosity of cassava by heat moisture treatment," Starch, vol. 45, pp. 131-1135, 1993.

[10] J. W. Donovan, K. Lorenz, and K. Kulp, "Differential scanning calorimetry of heat-moisture treated wheat and potato starches," Cereal Chemistry, vol. 60, pp. 381-3387, 1983.

[11] R. Hoover and T. Vasanthan, "Effect of heat-moisture treatment on the structure and physicochemical properties of cereal, legume, and tuber starches," Carbohydrate Research, vol. 252, pp. 33-53, 1994.

[12] R. C. Eerlingen, H. Jacobs, H. Van Win, and J. A. Delcour, "Effect of hydrothermal treatment on the gelatinisation properties of potato starch as measured by differential scanning calorimetry," Journal of Thermal Analysis, vol. 47, no. 5, pp. 1229-1246, 1996.

[13] Y. Takeda, A. Suzuki, and S. Hizukuri, "Influence of steeping conditions for kernels on some properties of corn starch," Starch, vol. 40, no. 4, pp. 132-1135, 1988.
[14] A. Gunaratne, A. Bentota, Y. Z. Cai, L. Collado, and H. Corke, "Functional, digestibility, and antioxidant properties of brown and polished rice flour from traditional and new-improved varieties grown in Sri Lanka," Starch, vol. 63, no. 8, pp. 485-492, 2011.

[15] L. Sair, "Heat-moisture treatment of starches," Cereal Chemistry, vol. 44, pp. 8-26, 1967. 


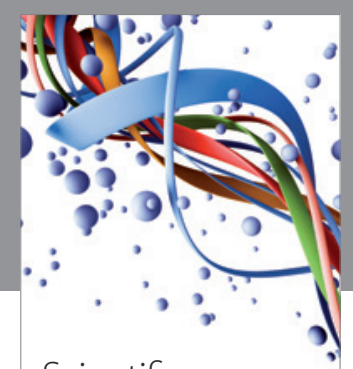

Scientifica
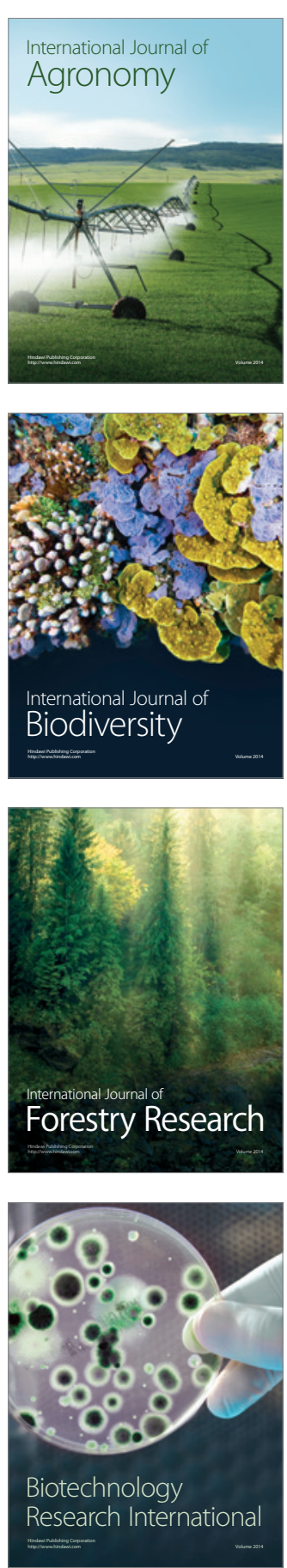
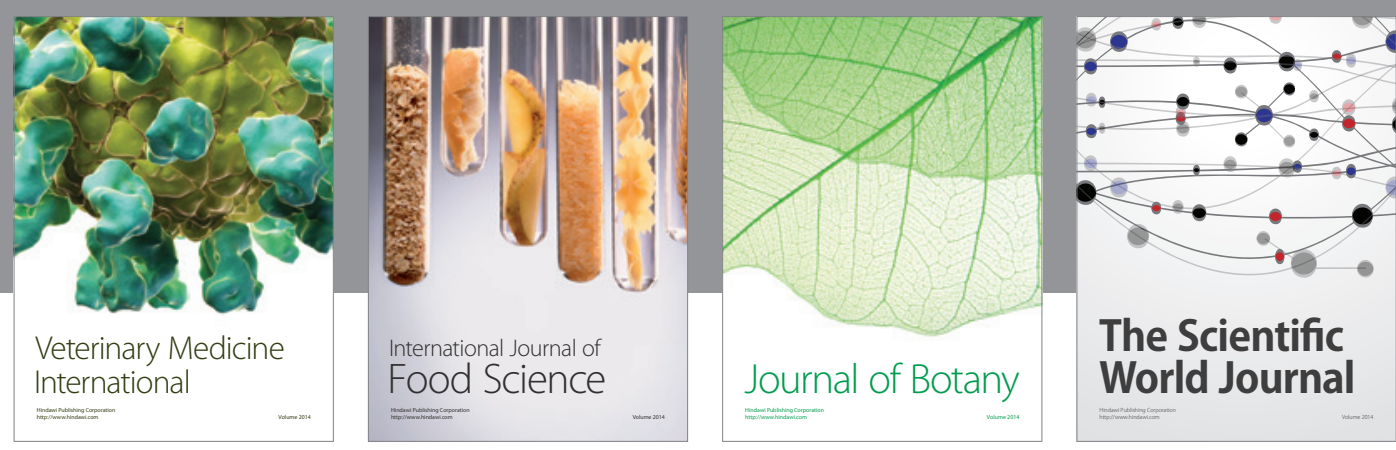

The Scientific World Journal
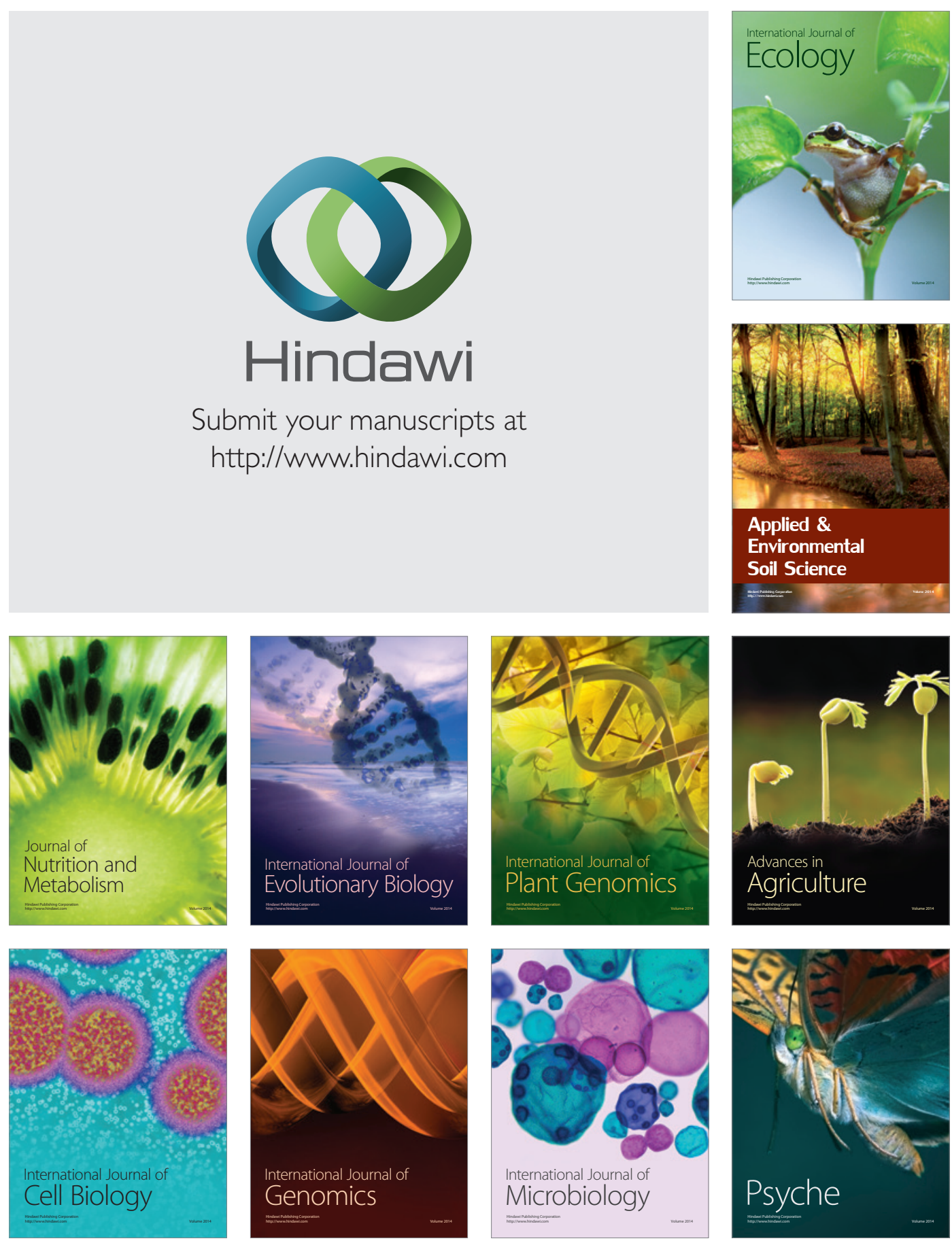